\title{
Vestimentas indisciplinadas en la escena contracultural de los años 80
}

\section{Lucena, Daniela; Laboureau, Gisela}

Resumen:

Este trabajo se refiere a una serie de prácticas estéticas desarrolladas por distintos actores del campo del arte, del rock y del teatro en los años 80 en la Ciudad de Buenos Aires, que fueron reconstruidas a partir de entrevistas en profundidad y el rastreo de fotografías y videos de la época. Se trata de experiencias en las que el cuerpovestido jugó un rol central: como soporte de lo artístico, como territorio de resistencia e indisciplina, como lienzo, como instrumento de protesta, como superficie de exploración y como vehículo de estar (con otros) en el mundo. El análisis de estas estéticas disruptivas se realizará prestando especial atención a las prácticas

Cuadernos del Centro de Estudios de Diseño y Comunicación Nº76

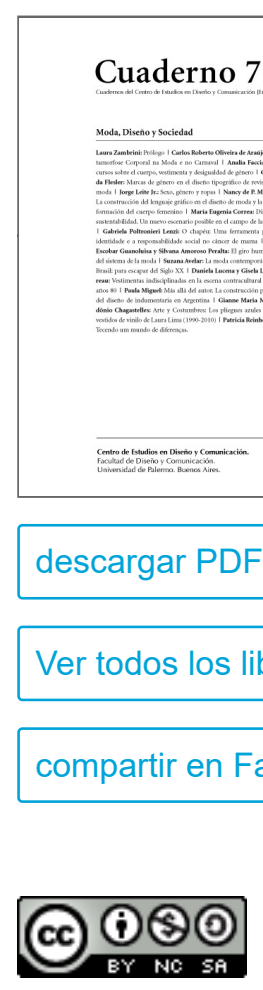

ISSN: 1668-0227

Moda, Diseño y

Sociedad

Año XX, Diciembre 2019, Buenos Aires, Argentina | 242 páginas

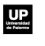

四

\section{ver índice de la publicación}

ros de la publicación

acebook

Esta obra está bajo una Licencia Creative Commons Atribución-NoComercialCompartirlgual 4.0 Internacional

vestimentarias desarrolladas por los

artistas, a partir de la hipótesis de que las mismas pueden ser leídas en un inédito cruce entre arte, moda y (micro) política.

Palabras clave: prácticas vestimentarias - moda - contracultura - rock - performance

(*) Daniela Lucena: Socióloga y Doctora en Ciencias Sociales por la Universidad de Buenos Aires (UBA). Investigadora del Consejo Nacional de Investigaciones Científicas y Técnicas (CONICET) y docente de grado y de posgrado en la UBA, la Universidad Nacional de las Artes y FLACSO, Argentina.

$\left.{ }^{(* *}\right)$ Gisela Laboureau: Socióloga y Doctoranda de la Facultad de Ciencias Sociales de la Universidad de Buenos Aires (UBA). Coordinadora del posgrado en Sociología del Diseño de la UBA; docente de grado y de posgrado en la UBA y en la Universidad de Palermo. 
La década de 1980 estuvo signada, en Argentina, por el fin de la última dictadura militar y el retorno a la vida democrática. En ese contexto, fueron muchos los artistas, músicos y actores que intervinieron activamente en la configuración de un entramado de sociabilidad y producción artística caracterizado fundamentalmente por su impronta precaria, irreverente y festiva (Lucena y Laboureau, 2014). "Entre el terror y la fiesta" (Longoni 2013, p. 2), el circuito del llamado under porteño supo albergar gran parte de esas acciones marginales, que se distanciaban de los valores estéticos dominantes y proponían nuevos modos colaborativos de hacer arte y política. Este trabajo se refiere a una serie de prácticas estéticas desarrolladas por distintos actores del campo del arte, del rock y del teatro en los años 80 en la ciudad de Buenos Aires, que fueron reconstruidas a partir de entrevistas en profundidad y el rastreo de fotografías y videos de la época. Se trata de experiencias en las que el cuerpo-vestido jugó un rol central: como soporte de lo artístico, como territorio de resistencia e indisciplina, como lienzo, como instrumento de protesta, como superficie de exploración y como vehículo de estar (con otros) en el mundo. El análisis de estas estéticas disruptivas se realizó prestando especial atención a las prácticas vestimentarias desarrolladas por los artistas, a partir de la hipótesis de que las mismas pueden ser leídas en un inédito cruce entre arte, moda y (micro) política.

\section{La experiencia represiva}

Comencemos entonces delimitando el acto del vestir como un hecho social en el más clásico sentido durkhemiano: como un modo de hacer que ejerce sobre el individuo una coacción exterior y que, si bien puede ser general en una sociedad, tiene una existencia propia más allá de sus manifestaciones individuales (Durkheim, 1982, p. 45). De allí que las prácticas vestimentarias sean el resultado de las coacciones sociales y conlleven fuertes imperativos morales que hacen que las propiedades o características atribuidas a la ropa se trasladen sin más a la persona que la utiliza. Por eso, el análisis de las influencias que ejercen las estructuras sociales sobre el cuerpo-vestido requiere considerar las diversas coacciones sociales que operan como restricciones o limitaciones sobre las prácticas vestimentarias en un momento histórico particular. En nuestro país, si bien ya desde el régimen militar liderado por Juan Carlos Onganía (1966-1970), los jóvenes se habían convertido en un actor social sospechoso (tanto por su creciente politización como por promover estilos de vida alternativos, alejados de la moral occidental y cristiana); la última dictadura profundizó ferozmente el accionar represivo contra los sectores juveniles a fin de desarticular sus lazos de identidad y pertenencia política y cultural. Desde la óptica de la Junta Militar, los jóvenes se dividían en tres grupos: "los enemigos-subversivos, los heroicos-virtuosos y los indiferentes-desorientados" (González, 2014, p. 203), siendo estos últimos los que debían ser especialmente resguardados de las ideas subversivas. Así es que, en el marco de su plan de terror sistemático, basado en el disciplinamiento, la tortura y la desaparición de los cuerpos, la dictadura iniciada en 1976 se ocupó también de delimitar y regular las conductas y apariencias deseables para los jóvenes utilizando al sistema educativo como su principal aliado. En este sentido, resulta elocuente una resolución del Colegio Nacional de Buenos Aires del año 1976 firmada por el Rector Eduardo Aníbal Ró- mulo Maniglia (Citado en Ministerio de Educación de la Nación Argentina, 2010, p. 79), que puede servirnos para ilustrar uno de los tantos modos en que operaba la represión en las escuelas secundarias en aquella época. En ese documento, las prácticas vestimentarias se consideraban algo más que una mera elección estética y se definían a partir de la trama de relaciones sociales en que se hallan imbricadas: "la vestimenta y aspecto exterior es también un medio de comunicación anunciador de la íntima estructura espiritual, del ambiente formador del individuo y de los estímulos primordiales a los cuales responde". 
De allí la necesidad de reglamentar las normas de presentación y la apariencia de los estudiantes de la institución:

a. Alumnas: pollera gris hasta la rodilla; saco azul oscuro liso, blusa blanca o celeste; zapatos bajos negros o marrones; medias enteras o tres cuartos de color azul; cabello peinado y tomado con vincha azul o negra; ninguna clase de maquillaje en el rostro ni alhajas o similares.

b. Alumnos: pantalón gris; saco azul oscuro liso; camisa blanca o celeste; corbata oscura lisa; zapatos bajos negros o marrones; cabello corto a dos dedos por encima del cuello de la camisa; rostro afeitado; patillas hasta la mitad del lóbulo de la oreja.

Si la vestimenta desaliñada aparece como sinónimo de depravación moral y anti patriotismo, se vuelve indispensable regular qué tipo de prendas y adornos podían usarse y cómo, de modo de uniformar el aspecto y los comportamientos, con el consiguiente castigo a quienes no se amoldasen a esas exigencias. En sintonía con este estricto reglamento, apareció con mucha presencia en los testimonios de nuestros entrevistados el recuerdo del tránsito por la escuela secundaria, durante los años de la última dictadura militar, como una experiencia represiva. También rememoran que esas normas iban más allá de los muros de la institución educativa, permeando todo el funcionamiento de un orden moral-social que se manifestaba incluso hasta en las prendas y en los colores. Así lo describe la periodista Ana Torrejón al evocar su regreso de España en 1979, tras lo cual integró en Buenos Aires el grupo de performers Las Inalámbricas:

Yo registro en mis emociones más profundas la sensación de la calle, del no poder transitarla y de la imposibilidad de la diferencia. (...) Cuando volví de España mi sensación de angustia total tenía que ver con lo limpias y lo vacías que estaban las calles. Yo tengo la idea de volver de Ezeiza y sentir esa tremenda angustia porque Buenos Aires era una ciudad que vos la veías como impoluta, impecable, re cuadriculada... y sentía eso en la calle... estaba todo muy codificado (Torrejón, 2014).

Resulta interesante que esta percepción del espacio público como un lugar estructurado, gris e intolerante, surge también de modo muy similar, en los testimonios de otros entrevistados de la misma generación de Torrejón. La actriz Katja Alemann, el músico Daniel Melero, la bajista Claudia Sinesi (ex integrante del grupo Viudas e Hijas de Roque Enroll), los artistas Marula Dicomo y Diego Fontanet y la actriz María José Gabin, por ejemplo, han utilizado términos y expresiones que se encuentran en sintonía con la descripción de nuestra entrevistada, para referirse al autoritarismo que se vivía en las calles de Buenos Aires (Lucena y Laboureau, 2016). Es notable, en este sentido, que el miedo y la censura no cesaron automáticamente tras el regreso de la democracia en diciembre de 1983, sino que continuaron presentes como modos de subjetivación y relación social aún finalizada la dictadura. El filósofo Pablo Dreizik, que en esos años estudiaba en la Universidad de Buenos Aires, lo sintetizó del siguiente modo: "se percibía un ambiente un tanto oscuro, dark, pesado... había miedo en la calle, Buenos Aires estaba muy panóptico" (2017). Asimismo, esos recuerdos contrastan notablemente con la sensación de libertad experimentada en los espacios nocturnos del circuito under de la ciudad. En ese entramado contracultural, fueron varios los artistas que eligieron la vestimenta, el cuerpo-vestido, como territorio de comunicación, fuga y desobediencia. Si bien, la moda con sus mandatos coercitivos tiende a uniformar y homogeneizar los cuerpos generizados, puede ser también un instrumento de expresión y diferenciación desde el cual transmitir otros sentidos y significados que escapen a la coerción y la disciplina. 
Antes de avanzar sobre las prácticas vestimentarias de los protagonistas del under porteño, es necesario reponer las características, tanto de la moda como de la anti-moda, durante esos años. Mientras en el país se aceleraba el proceso de desindustrialización y el sector textil se veía aplastado por políticas económicas que promovían el desvío del capital hacia sectores no productivos y la apertura de las importaciones; las tendencias hegemónicas de la moda local privilegiaban la uniformidad, configurando una estética "anodina y homogeneizadora" (Saulquin, 2011, p. 183). La mayoría de los jóvenes de los sectores medios y altos privilegiaban los estilos basados en las grandes marcas internacionales que debían ser exhibidas, además, de modo bien notorio en el exterior de las prendas. "Fue en ese momento y en pleno desarrollo del hipermarquismo cuando los tradicionales talles fueron reemplazados por medidas internacionales: small, medium, large" (Saulquin, 2011, p. 183), haciendo que los cuerpos se desdibujen en sus particularidades para adecuarse a las medidas generales. Las revistas de moda reinterpretaban entonces los estilos juveniles de los centros urbanos internacionales en clave nacionalista y costumbrista como modos legítimos de vestir y adornar el cuerpo. A partir de la segunda mitad de los años 70, proponían para los jóvenes el estilo disco, que "reforzaba la imagen de una juventud satisfecha y divertida" (Pujol, 2011, p. 92) y una moda folk que destacaba los valores de lo autóctono y la tradición. Contra estas tendencias, la anti-moda hippie aparecía como la alternativa para quienes no se sentían interpelados por esas modas impuestas por el mercado.

En relación con ese escenario, varios entrevistados hicieron referencia a la incomodidad que sentían por las estéticas y estilos propuestos por la industria de la moda. Katja Alemann describió la Buenos Aires de entonces destacando lo unifome de la estética que se veía en las calles:

Era un horror. Todo el mundo vestido de gris y azul, todo el mundo más o menos igual. Las minas súper histéricas, todas flaquitas, todas preciositas, con los culos bien ajustados como siempre, pero mucho más que ahora. Mucho más llevadas a una cosa bien standard de lo que sería la seducción (2011).

Ana Torrejón, por su parte, señala sus dificultades estéticas e ideológicas con las tendencias de la moda de entonces, con las que se sentía incómoda debido al uso de los colores y los brillos y lo que icónicamente simbolizaban: "La verdad es que estaba mucho más deprimida. Nunca fui disco, me parecía terriblemente capitalista ese discurso. Y la naturaleza me quedaba fatal, el hipismo nunca me quedó, no me va, soy demasiado filosa" (Torrejón, 2011).

De la desidentificación con las propuestas que vestían las vidrieras, pero también con el estilo de la anti-moda hippie, surgió en varios de los artistas la necesidad de buscar sus prendas en mercados de pulgas o anticuarios, tal como describe Marula Di Como, cuando cuenta que el grupo que se reunía en Bolivia no viajaba a Europa para traer sus prendas, pero sí a Pompeya: "Los viajes eran al cottolengo Don Orione. Era ir a Pompeya y el viaje en sí mismo era recorrer el cottolengo viendo telas, texturas. Ese era el verdadero viaje" (2016). El acto del vestido se transformaba así en una experiencia afectiva y placentera de búsqueda. Cargar las prendas de significado, atribuirles un carácter simbólico y afectivo, buscar y encontrar esas prendas de estéticas tan disímiles en viejas tiendas y mercados, nos permitía vislumbrar los pliegues de un ropaje que atesoraba en su interior momentos lúdicos y placenteros. Para muchos de los artistas entrevistados fueron esas prendas con historia las que, al quedar demodé y recombinarse en un tiempo y un espacio ajenos a sus orígenes, le permitieron desarrollar una suerte de protesta del traje (Riviere, 1977) que pretendía ser también una rebelión 
contra la moda oficial, tan insoportable como las normas de ese orden social autoritario que en ella se expresaban.

Modo mata moda: las estéticas del rock

Un ámbito significativo en cuanto a las elecciones vestimentarias de sus protagonistas es, sin dudas, el mundo del rock. Las prendas elegidas para cada show o para cada experiencia eran pensadas cuidadosamente por quienes conformaron, a partir de prácticas vestimentarias indisciplinadas, una identidad singular capaz de desoír los convenios que delimitan lo aceptable. El músico Daniel Melero, por ejemplo, diferencia entre modo y moda para referirse a esa dimensión creativa del vestir y su interés por generar un estilo propio desde los años en que tocaba con su grupo Los Encargados:

El modo mata moda, de eso estoy seguro. Cómo llevás lo que no es moda te convierte en una persona que tiene un estilo moderno. Para entrar en la tribu del estilo, muy distinto que tener la ropa que esté de moda es el modo de la elección, es el modo en que se lleva lo que cuenta (2011).

Efectivamente, desde aquellos años el músico cultivó un estilo que en su originalidad y singularidad logró perdurar más allá de la moda, constitutivamente efímera, cambiante y pasajera. Pero si de músicos de rock se trata, el caso de Federico Moura sea quizá el más emblemático. Desde mediados de los años 70 Federico estuvo al frente de sus propios locales de ropa Limbo y Mambo en la Galería Jardín de la calle Florida, donde se podían encontrar prendas que diferían de las estéticas frecuentes en la mayoría de los jóvenes. El músico, además, tenía un gran interés por la decoración y se ocupaba de darle a la distribución espacial de los locales su impronta personal, realizando las vidrieras y logrando una estética despojada, austera y de un orden milimétrico en la forma de presentar la ropa (Lucena y Laboureau, 2015). Su hermano Julio recuerda que Federico "estaba implicado en todo el proceso del diseño de la ropa -desde los moldes hasta ir al barrio de Once a buscar las telas- le dedicaba mucho tiempo al asunto" (Lescano, 2010, p. 40). Por otra parte, los desfiles que Federico organizaba junto con el artista Juan Risuleo en el Hotel Claridge planteaban una puesta en escena que subvertía las formas tradicionales del uso del espacio, ya que la propuesta consistía en que el público se ubicara a la misma altura de las modelos para que no quedaran limitados a ver solamente los pies.

Luego de esas experiencias, Federico creó junto con sus hermanos el grupo de rock-pop Virus, que durante sus primeros años de existencia tuvo que lidiar con las duras críticas de otros rockeros, de los periodistas y del público. Los ajustados pantalones y las estridentes musculosas que vestían los miembros del grupo, la sensual silueta espigada y el aire andrógino de su cantante, la breve duración de las canciones, las puestas de luces y las cuidadas coreografías eran elementos disruptivos que contradecían abierta e insolentemente los mandatos imperantes del rock argentino. Durante los años 70, se había acentuado en el ámbito del llamado rock nacional la supremacía de lo intelectual/mental sobre el cuerpo y los sentidos. En esos años el baile, modo de interrelación donde el cuerpo adquiere un rol privilegiado, quedaba circunscripto al espacio de la discoteca. Allí, según los rockeros, sonaba la música comercial, divertida y descomprometida que atentaba contra la consolidación de un espíritu juvenil crítico colectivo, que en cambio sí podía conformarse en el espacio trascendental del recital, donde el público escuchaba sentado. Para Virus, sin embargo, era fundamental propiciar la diversión, el baile y la alegría en los recitales para generar un estado distinto a la tristeza y al desánimo -algo especialmente significativo si se tiene en cuenta que Jorge Moura, el hermano mayor de los músicos del grupo, fue secuestrado en 1977 y continúa desparecido hasta el día de hoy. Federico consideraba 
que en un auténtico concierto de rock and roll el público debía estar en movimiento y por eso no dudaba en levantar las butacas de los teatros antes de una de sus presentaciones, para que la gente bailara libremente a partir de la música y no temiese poner el cuerpo en acción. "Hay mucha gente que cree que atender el cuerpo es una cosa estúpida, que bailar es perder el tiempo. Yo creo que atender el cuerpo es igual que atender la mente: es tan elevado lo uno como lo otro", respondía Federico a quienes lo tildaban de hedonista y superficial por proponer un cuerpo que no sólo sea blanco y objeto de la violencia y la represión, sino también una superficie de placer.

Travolta o Spinetta. Jóvenes frívolos en la disco o jóvenes comprometidos en el recital. Virtuosismo del músico o destreza del bailarín. Música comercial/frívola o música no comercial/contestataria. Moda o contracultura. Derecha o izquierda. El cuerpo o la mente. Virus, con su disruptiva propuesta estética que inscribía sus raíces en aquel primer rock bailable de El Club del Clan y Sandro, se animaba a conjugar tendencias contrapuestas y a desarticular los binarismos que cimentaban los valores constitutivos del campo del rock nacional. Ubicarse por fuera de esa lógica polarizada los colocaba en el lugar de lo inadmisible, de la burla y la sospecha. Solo recién a partir del retorno de la democracia el rock argentino comenzaría a alejarse de la solemnidad y se daría el permiso para admitir la alegría, el baile y los colores estridentes como parte de su propuesta.

Poner vida y paradoja

Si pensamos en la utilización del cuerpo-vestido como territorio de fuga y experimentación, resulta ineludibe mencionar al grupo Las Inalámbricas -liderado por Ana Torrejón e integrado por Cecilia Torrejón, Paula Serrat, Ximena Estévez y Guillermina Rozencratz. De un modo conciente y programático, este colectivo de mujeres hizo del vestido una herramienta de comunicación, intervención y creación artística. Desde el comienzo fue Torrejón quien se encargó del diseño de las prendas para las intervenciones, confeccionadas con cortes baratos y ropas compradas en mercados de pulgas o viejas casas de batones y uniformes.

Una particular característica de los trajes que usaban Las Inalámbricas fue la variedad de materiales y la revalorización de objetos y texturas que usualmente no se utilizan en la indumentaria, como flores y frutas de plástico, manteles de hule, papeles, cortinas de baño y discos de vinilo. Sus elecciones, que tendían a la fusión y a la mezcla que tensiona las fronteras entre lo sofisticado y lo vulgar, lo superficial y lo auténtico o lo serio y lo gracioso, dialogaba muy bien con la declaración del grupo: todas tenemos diploma de corte y confección. Esa frase con que Las Inalámbricas se autodefinían, conlleva un gesto irónico hacia la canción Corte y Confección que Nicky Jones interpretaba en el popular programa musical televisivo de los años 60 El Club del Clan, pero también "un maquillaje" (2014) para enmascarar sus intervenciones como algo inofensivo ligado al mundo frívolo de la moda. Sin embargo, más allá del camuflaje, declararse poseedoras de ese diploma implicaba una reivindicación -por parte de mujeres profesionales o estudiantes universitarias- de un oficio doméstico, típicamente femenino y de menor jerarquía que el diseño o la alta costura (a los que sí se dedican los hombres). Estas actitudes configuran uno de los rasgos más destacables de la estética del grupo: la permanente desdiferenciación entre alta cultura y cultura de masas y la insistencia en la mixtura entre géneros, disciplinas y materiales que busca desdibujar los bordes entre lo artístico y la vida cotidiana.

Algunas de las intervenciones del grupo tuvieron lugar en fiestas nocturnas privadas, casamientos o cumpleaños, a los que en muchos casos no habían sido invitadas. Esas acciones realizadas "en contextos muy burgueses" (Torrejón, 2014) se proponían generar una especie de extrañamiento a partir de la creación de 
situaciones o relaciones imprevistas. Otra forma de intervención habitual del grupo eran las acciones de pintura en vivo realizadas junto con el trío Loxon, compuesto por los artistas plásticos Rafael Bueno, Guillermo Conte y Majo Okner. Las presentaciones de Las Inalámbricas junto con los Loxon, que se anunciaban como "pintura en vivo", trascurrían generalmente en el marco de esa vida paralela: en espacios nocturnos periféricos y marginales del campo cultural de la época, caracterizados por su impronta precaria y festiva, donde eran frecuentes las producciones estéticas multidisciplinarias y colaborativas (Lucena y Laboureau, 2014). Mientras tocaban grupos de rock o actuaban distintos artistas, el trío Loxon pintaba los vestidos portados por los cuerpos de las mujeres en una suerte de performance que evoca las acciones de una vasta zona de la vanguardia histórica de la primera mitad del siglo XX1 .

En el caso de la pintura en vivo de Las Inalámbricas y el trío Loxon, deben destacarse algunas particularidades que le dan su sello propio a la acción. Se trata de vestidos negros creados por Ana Torrejón especialmente para ser intervenidos por el pincel esa noche. Sobre esas telas los artistas pintaban con Loxon, una pintura sumamente resistente utilizada por pintores y albañiles para pintar casas. O sea, no eran los llamados materiales nobles como oleos o acrílicos los que se empleaban, sino una pintura propia del mundo de la construcción y no de las Bellas Artes, que aparte de ser barata tenía la ventaja de adherirse bien a las telas y perdurar más allá de los lavados. Además, luego de terminar esas pinturas los vestidos eran regalados o sorteados entre los asistentes de esa noche, rasgo que favorecía una circulación alternativa (y no reproductiva) de las obras, al mismo tiempo que invitaba a que otro cuerpo vista esa prenda en otros espacios y tiempos distintos.

Por último, encontramos una serie de acciones donde la propuesta del grupo era "posicionarse como un objeto cuasi-escultórico" (Torrejón, 2011). "Hay que ser una obra de arte o revestirse de una obra de arte", proponía Oscar Wilde (1894), y en los cuerpos de estas mujeres parece encarnarse ese mandato. Una cuidadosa y selectiva configuración de telas, colores y texturas que se traducía en trajes únicos en su estilo es lo que permitía la transformación del cuerpo en arte. Un cuerpo inútil e improductivo en los términos de la lógica instrumental de la fuerza de trabajo capitalista, cuya única función era explorar sus propias posibilidades plásticas y activar experiencias perceptivas y creativas. Lo artístico aparecía entonces enmascarado como la propia vida y ese cuerpo maquillado, peinado y adornado se convertía en el soporte de una práctica estética que buscaba "poner vida y paradoja en los rituales sociales" (Torrejón, 2011). Con su mera presencia, los cuerposvestidos de esas mujeres que traían imágenes de distintas décadas recodificadas a partir del presente, provocaban sorpresa y llamaban la atención al modo de signos de interrogación o exclamación que desorganizaban la lógica de los mecanismos sociales que regulan los comportamientos. Desde el presente, Torrejón vuelve sobre esas acciones y reflexiona: "en un contexto de tanta ausencia la presencia con aparente sin sentido era elocuente" (2011). Una elocuencia asumida y transmitida por cuerpos que se sabían vulnerables pero que sin embargo actuaban como un territorio desde el cual provocar nuevos sentidos capaces de interpelar la normalidad cotidiana.

Traperos de la ciudad

En el imaginario del under subyacía una "hermandad descartada" (Garbatzky, 2013, p. 99) que dio lugar a un nuevo modo de vinculación con los objetos. Si pensamos que a través de las metáforas arquitectónicas se establecen vínculos entre las funciones de la casa y la ropa (Flugel, 1964) encontramos por parte de muchos de los protagonistas de esas experiencias, un particular modo en el cual habitaron sus cuerpos desde una 
arquitectura del desecho. Como recuerda Vanesa Weinberg, miembro del dúo Las Hermanas Nervio, la calle era el lugar "donde encontrar tesoros inesperados" (Lucena y Laboureau, 2016, p. 253). También Manuel Hermelo se refirió a la ciudad como un ámbito fundamental de búsqueda de los materiales que necesitaban en La Organización Negro para sus acciones, de allí que afirma: "fuimos los primeros cartoneros" (Lucena y Laboureau, 2016, p. 48). Encontraban una materialidad desplazada en las calles de la ciudad de Buenos Aires a la cual le devolvían sacralidad. Los desperdicios eran a los ojos de estos artistas valiosos descubrimientos que insertos en nuevas combinaciones creativas se redimían en una segunda existencia.

El desafío al cual se enfrentaban generó una particular estética como lo recuerda Alemman: "siempre laburábamos con lo que había" (2011). Las limitaciones económicas no fueron un impedimento, sino que por el contario les permitió no tener limitaciones externas que los condicionaran y les exigieran determinadas especificaciones estéticas. Omar Viola, haciendo alusión al Parakultural, sostenía que era un espacio que hablaba el lenguaje propio de la época: "Cómo la no existencia puede transformarse en existencia. Esa falta de confort estaba a favor y no en contra de lo que se quería decir" (1998). Aparecía de este modo un intersticio doble, el modo en el cual estos artistas miraron pero también se dejaron mirar por los objetos, hecho que es fundamental para producir tal experiencia creativa. Aquello que ha sido descartado por su falta de utilidad, es objeto de contemplación por quienes eran capaces de producir una restitución que conserva algo del aura que allí se encontraba oculto a los ojos de los transeúntes desprevenidos que no podían llevar su mirada más allá de lo tautológico. Cómo ese rostro de los objetos desechados que exclusivamente se volvieron hacia los artistas que lograron verlos y producir un efecto de restitución áurica, ha escrito Walter Benjamin:

(...) en la mirada se halla implícita la espera de ser recompensada por aquello hacia lo que se dirige. Si esta espera (que en el pensamiento puede asociarse igualmente bien a una mirada intencional de atención y a una mirada en el sentido literal de la palabra) se ve satisfecha, la mirada obtiene, en su plenitud, la experiencia del aura [...]. Quien es mirado o se cree mirado levanta los ojos. Advertir el aura de una cosa significa dotarla de la capacidad de mirar (Benjamin, 1972, p. 70).

La experiencia del aura que emerge en esa doble mirada, captura de algún modo una relación que se da con un cierto modo de ver y ser visto, que bajo determinadas condiciones moviliza un vínculo entre el sujeto y el objeto que posibilita tal experiencia (Benjamin, 1972). De este modo, la mirada no quedó vedada para todos ellos que pudieron ver más que residuos y se lanzaron a producir de un modo lúdico una experiencia estética que les otorgaba la impronta del bricoleur. Tal como es definido por Lévi-Strauss, es aquel que trabaja con fragmentos de obras ya elaboradas, con restos y sobras de la cultura. Esa composición hecha de fragmentos y restos, donde se produce el ensamblaje, nos habla de una experimentación que organiza el mundo con sus jirones. Esos desechos fueron a los ojos de estos artistas la imagen perfecta con la cual proyectar el modo de habitar su propio cuerpo y que nos habla de las condiciones históricas en las cuales estaban insertos también como desechos de una matriz temporal. Haciendo referencia a la figura del niño, Baudelaire escribió que: "(...) todo lo ve como novedad; está siempre embriagado" (1994, p. 13). Ese estado de ebriedad en el cual se encuentran los niños, es el que los dota de un valioso atributo, la embriaguez de una mirada que da cuenta de una sensibilidad que ocupa todo su ser, no sólo ante la novedad sino incluso ante la monotonía de lo cotidiano. Un estado de ebriedad que hace del genio: "(...) un hombre-niño, un hombre que posee cada minuto el genio de la infancia, es decir un genio para el que ningún aspecto de la vida está embotado" (Baudelaire, 1994, p. 15). 
Ese particular vínculo que entabla el niño con los objetos nos permite pensar una relación de semejanza con el modo creativo con el cual esta generación de artistas se relacionó con los desechos. Una visión que de un modo sugerente podría ponerse en diálogo con la concepción que María Moreno tendrá de la generación de 1980 al pensarla como una suerte de pasaje a un cuerpo infantil donde:

El cuerpo de los ochenta podría ser el de un bebé que juega con sus heces, hace estragos con un maletín de maquillaje y en vez de hablar hace glosolalia y se tira pedos. Aunque adquiera las formas maduras del monólogo poético, la murga de famosos y la ambientación que se deteriora antes de inaugurar (Moreno, 2003, p. 5).

Una percepción infantil que les permitía quedar fascinados con una piedra por su extraño color o recibir con algarabía las medias usadas que una vecina les regalaba para los carnavales.

Batato Barea, quien se autodefinía como clown-travesti-literario, es recordado como el mesías de esta generación y su "hermandad descartada". Todos los que lo recuerdan ponen especial énfasis en su particular relación con los desechos, quienes lo conocieron coinciden en afirmar que le encantaba revolver en la basura. Desde diferentes registros confeccionaba él mismo sus vestuarios, con materiales que reciclaba de la basura o de aquello que le regalaban, y componía de este modo una estética inigualable. En palabras de Noy su estilo era aquel que "nacía de lo ciruja que era" (Friera, 2001, p. 2) donde los desechos levantados de las cajas de basura componían su poética corporal arriba del escenario pero también en su vida cotidiana. Con el mismo afán con que los niños se ven atraídos por coleccionar objetos, Batato juntaba golosinas para hacerse un "Vestidobanquete" como él mismo lo llamó. Estaba atravesado por una imaginación creadora y justamente será María Moreno quien evocará a Batato como un niño, y María José Gabin como "un niño con tetas" (Dubatti, 1995, p. 177). En sus creaciones supo verse como los niños que se encuentran:

(...) irresistiblemente atraídos por los desechos de la construcción, la jardinería, el trabajo doméstico, la costura o la carpintería. En los productos de desecho reconocen el rostro que el mundo de las cosas vuelve directa y exclusivamente hacia ellos. Al utilizar estas cosas, no es que imiten el mundo de los adultos, sino que en los artefactos que producen al jugar, juntan materiales muy diferentes entre sí en una relación nueva e intuitiva (Benjamin, 2005, p. 223).

\section{Habitar el desecho}

Uno de los vestidos más recordados de Batato, fue el que usó para participar como concursante del Festival del Body Art2 . Durante el año 1988 se organizaron cuatro Museos Bailables, donde se convocaron artistas de diversas disciplinas para que ocupasen por una noche el espacio de una discoteca. El festival del Body Art, fue el cuarto y último de ellos organizado por Roberto Jacoby junto a Coco Bedoya y Mercedes Idogaya que tuvo cita en la discoteca Paladium (Longoni, 2012; Bevacqua, 2013). La propuesta se anunciaba en la convocatoria del concurso y muestra como: "Con el arte en el cuerpo ¡La imagen viva de Buenos Aires!"3 . La noche del Body Art proponía una bifurcación que escapaba de los dictadores de la moda para desencadenar la imaginación de quienes pudieran crear un cuerpo donde arte y moda se fusionara en un mismo proyecto de construcción. Sin ningún tipo de restricciones se invitada de modo abierto a quienes quisieran participar. Cada uno podía producir su propia imagen o producir a alguien "como Obra de Arte, como Imagen Viva, que respira, camina y habla" como lo anunciaba el manifiesto de la convocatoria, aquel que ganase a través del aplauso del público podía obtener, no sólo el premio que se ofrecía de 200 dólares, sino ser famoso por 15 segundos, haciendo referencia 
a la conocida expresión de Andy Warhol sobre el futuro derecho de todos a un momento efímero de gloria. María Moreno recuerda cómo fue el origen de aquel indumento que llevó Batato aquella noche para el concurso: “Jorge Gumier Maier, otro artista cartonero exiliado en las islas del Delta, a quien el río lo exime de revolver containers, fue su couturier en el concurso de body art de Jacoby. Batato le había llevado a su casa de la calle Mansilla metros y metros de papel plisado sacado de la basura. Él lo hizo "ponible"; el diseño era de Batato, que se lo armó encima sin esperar el caminito de alfileres (se llamó El papelón) (María Moreno, 2011, p. 3).

El hecho a medida o Haute Couture, término fránces con el cual se denomina a la Alta Costura, es el resultado de piezas únicas e irrepetibles que se crean a pedido de un cliente individual y para esa persona en particular, lo cual las vuelve exclusivas y a medida de su portador. A su vez, un vestido de Alta Costura debe cumplir rigurosos estándares que son definidos por la Chambre Syndicale de la Haute Couture en París. La confección realizada a pedido de Batato por el couturier Gumier Maier no cumplía los patrones requeridos por la Cámara de la Alta Costura en París, pero en dicha dislocación espacial se produjo el cimbronazo de una contaminación rioplatense, como el camino del neo-barroso que propone Perlongher para pensar las formas de escrituras poéticas mancilladas por el barro del Río de la Plata. El papelón de Batato profanaba los principios de la Alta Costura, si bien estaba confeccionado a mano, artesanalmente, a pedido y medida de su "cliente" el material para su hechura lo alejaba de los textiles costosos y de alta calidad que son un requisito. Y en su lugar fue el papel crepe plisado de un local de Once que, como recuerda Gumier Maier, Batato encontró tirado en la calle.

Ubicados en otras coordenadas espacio/temporales, tanto Charles Baudelaire como Walter Benjamín, se vieron fascinados por la figura del trapero. Aquellas personas que se dedicaban a retirar la basura, los desperdicios de las modernas ciudades europeas hasta que aparecieron los servicios de recolección de basura. El mismo año en que París veía sentar las bases de la Alta Costura, con la inauguración en 1857 de la tienda del modisto Charles Worth, Baudelaire publicaba por primara vez Las flores del mal donde uno de sus poemas se intitulaba El vino de los traperos. En la figura del trapero, Baudelaire encontró la metáfora con la cual caracterizar al poeta moderno. "Trapero o poeta, a ambos les concierne la escoria; ambos persiguen solitarios su comercio en horas en que los ciudadanos se abandonan al sueño; incluso el gesto en los dos es el mismo" (Benjamin, 1972, p. 8). Del mismo modo en que el trapero recoge la escoria de la ciudad, el poeta hace de los desechos el objeto de su labor artística.

En un juego sutil de resonancias entre otro tiempo y latitud, Noy dirá de Batato que era un poema encarnado y recuerda que Olga Orozco le dijo alguna vez que: "en la vida no se puede dejar de ser poeta y que la poesía es una puesta en el mundo" (Friera, 2001, p. 2). Como trapero de la ciudad, Batato era la metáfora de un poema encarnado que había incluso incorporado el desecho industrial en su propio cuerpo cuando tomó la decisión de hacerse las tetas inyectándose aceite industrial4 . Con su cuerpo ignominioso, abyecto incluso monstruoso encarnó una resistencia a las corporalidades que soportan diariamente los embates mediatizados de la cultura que buscan socializarlos y normalizarlos para que se ajusten a los parámetros sociales que requiere el sistema social. Como recuerda Ana Torrejón: "El testimonio de Batato fue uno de los testimonios más viscerales y más interesantes, más dolorosos y más revolucionarios. Porque Batato no era la travesti linda, era el dolor, era la periferia, era un hombre con batón y uñas pintadas" (Lucena y Laboureau, 2016, p. 159). El camino que emprendió Batato desacomodaba la tríada cuerpo-vestidosociedad construyendo una perfomatividad vestimentaria donde: "Exultante, Batato creó un híper kitsch periférico bien nac. \& pop. (...) Lo suyo era el lujo oropel, como el de Ramona Montiel, que no imita ninguna moda: delata a simple vista su origen plebeyo" (Oybin, 2015 , p. 3). Su política corporal supo poner en marcha un proceso vital que encontró en el arte el resguardo en 
el cual asilarse para construir su bifurcación y producir el desborde cuando es la propia vida la que se vuelve obra de arte. Así es recordado por todos los que lo conocieron, como es el caso de María José Gabin quien trazando un puente con las vanguardias estéticas, en aquella identificación indivisible entre arte y vida le gusta recordar a Batato románticamente como un artista maldito: "Batato era un artista en su vida. Era en el escenario lo que era como persona" (Dubatti, 1995, p. 171). La propuesta con la cual Garbatzky (2013) nos invita a pensar su figura en la escena teatral de los años 80 es la de la obra- vivencia, donde no estaríamos frente a un actor que interpreta un personaje sino ante quien se presenta a sí mismo poniendo en juego su existencia en cada performance poética.

Resulta de gran interés recordar que cuando fue invitado por Vivi Tellas a una mesa en el ICI (Instituto de Cooperación Iberoamericana) para debatir: por qué el teatro se repetía, Tellas recuerda que cuando le tocó el turno a Batato sentenció que él nunca se repetía, y como prueba de tales palabras levantó su remera y mostró las tetas. En ese mismo gesto no sólo quedaron expuestos sus pechos sino las cicatrices de aquella intervención estética y política, donde Batato aseguraba que el busto se volvía un vestido más. Las mismas cicatrices que Fernando Noy había visto en otro momento chorrear y a Batato remendar con poxyran (Garbatzky 2013, p. 71) eran parte de los desechos que penetraban la materialidad de su cuerpo. El residuo urbano, el aceite industrial estaba allí incrustado en la carne como si las palabras estuvieran de más y en ese acto de improvisación su voz corporal, fuera capaz de reclamar el derecho del cuerpo a ser territorio habitado que se pronuncia sin palabras. Batato exponía una dimensión monstruosa de su cuerpo trastocado. Estaba orgulloso de su decisión aunque quienes lo acompañaron recuerdan lo doloroso que fue la intervención. En palabras de María Morena, Batato: "se puso tetas porque era un revolucionario" (Moreno, 2011, p. 2). Produjo una visualidad extrañada para quienes no podían comprender su explícita anomalía construida. Un cuerpo enigmático e inclasificable que generaba incomprensión, como cuando circulaba por el espacio público donde "nadie decía: "Es un trava. Él era otra cosa" (Dubatti, 1995, p. 177). Huída de las asignaciones binarias de género pero también de otros modos de construir identidades alternativas, como enfatiza Gabin era "un espécimen, un andrógino, una cosa irreal. Era algo muy fuerte: algo inclasificable. (...) Era una personalidad difícil de definir. Andrógino es el término que más me gusta" (Dubatti, 1995, p. 174).

La fotografía que tomó Julieta Steimberg de Batato vistiendo El Papelón aquella noche del Body Art hace confluir la superposición de al menos dos tiempos, el que da testimonio de lo que ha sido, pero al mismo tiempo el que contiene en su interior otra capa temporal, la de un tiempo futuro. Es ese tiempo por venir el que nos habla de la creación de un pueblo, el "pueblo que falta" al decir de Deleuze (1996, p. 9) no aquel que ya estaba dado sino el que era preciso crear, el que hacía falta inventar:

Su cuerpo fue vanguardia, irradiaba futuro, porque fue trans y queer mucho antes de que esas dos palabras siquiera circularan en la Argentina como consignas de rebelión de las dictaduras genéricas, porque su desafío a las convenciones se anticipaba a todo, se desataba de cualquier mandato, pero puntualmente estaba ahí antes de que se pudiese nombrar (Trerotola, 2011, p. 2).

En aquella fabulación creativa Batato se apropió de los desechos para crear de manera anticipada lo que como sostiene Tino Tinto en la actualidad sería una estética del reciclado. Si en palabras de Deleuze, "toda obra es un viaje, un trayecto" (1996, p. 10) su cuerpo vestido estaba allí como un virtual, formando parte de una realidad que inventaba en su presente otros futuros por venir. 
A lo largo de nuestro artículo hemos puesto el foco en las vestimentas que los artistas del llamado under porteño elegían para sus intervenciones, shows o performances y también en su vida cotidiana. Cuando hablamos de moda, pensamos no sólo en los estilos que siguen la lógica de los cambios regulados, regulares y no acumulativos propios de esa industria, sino también a las prácticas vestimentarias desarrolladas por los individuos. Vestirse es un acto íntimo e individual que prepara a las personas para la vida social: los cuerpos sociales son cuerpos vestidos y es justamente el vestido el que los vuelve reconocibles (y significativos) culturalmente (Entwistle, 2002). En los años estudiados pudimos observar la irrupción de novedosas estéticas vestimentarias como soportes de nuevas de subjetivación antagónicas o contraculturales. Para contextualizar esas prácticas del vestir consideramos significativo que en el marco de su accionar represivo y desaparecedor la última dictadura militar delineó también estrictas pautas estéticas y vestimentarias para los jóvenes. Los testimonios de la mayoría de los entrevistados dan cuenta de ese orden social, que se cristalizaba también en la indumentaria, cuando relatan las agresiones sufridas en la calle a raíz de sus elecciones vestimentarias, que desafiaban los límites del gusto legítimo y la apariencia deseable. Aquellos cuerpos que irrumpían en el espacio público atentando contra las costumbres eran colocados en un lugar potencialmente subversivo, generando la molestia y la incomprensión de muchos ciudadanos que, habiendo interiorizado los mecanismos de censura y obediencia, condenaba y sancionaba dichas transgresiones a la hora de tratar con la diferencia. Las descripciones de los artistas sobre lo censuradora que era "la calle" nos acercaban a la advertencia de Pilar Calveiro: "la represión consiste en actos arraigados en la cotidianidad de la sociedad, por eso es posible" (1998, p. 32).

Aquellos encuentros que se daban cara a cara en la esfera pública nos permitían repensar la cotidianeidad en la cual los cuerpos circulaban en un espacio reglado, que custodiaba un modo de vestir "adecuado" y "correcto", siendo en muchos casos estas actitudes las que continuaron aún luego de finalizada la dictadura. No obstante, en esos años marcados por el accionar de un poder desaparecedor que dispersó el terror dentro y fuera de los centros clandestinos de detención, estas vestimentas revulsivas encarnaron formas de resistencia frente a los efectos represivos y moralizantes de los dispositivos dictatoriales. Prácticas desobedientes inscriptas en un campo de luchas por y a través del cuerpo, que encarnaron una indisciplina capaz de rebelarse audazmente contra la asignación política de seguir siendo el mismo. Encontraron en ese contexto el desafío de romper con la sensación de transitar una realidad apagada y descolorida a través, no sólo de las formas, sino de los colores con los cuales decidieron vestirse. Recuperar una paleta de colores perdida fue entonces la apuesta de muchos de ellos, a través de la utilización de coloridas prendas y vestuarios y también de una ecléctica ambientación de los espacios que creaban. Venciendo las censuras y las descalificaciones, en estas experiencias el color se expandió para invadirlo todo, redimensionando una visualidad estruendosa de formas, apariencias y tonalidades que componía un colorido collage, que sería mirado con desconfianza por quienes no podían decodificar esos cuerpos ensamblados que expresaban nuevos estados de ánimo. Las palabras de los protagonistas y el diverso material al cual tuvimos acceso nos permitió rastrear estas experiencias vestimentarias pero también nos desafió indefectiblemente a la pregunta: si aprendemos a vestirnos del mismo modo que aprendemos un lenguaje, es decir, como un sistema de comunicación aunque no verbal pero dentro del cual se ponen en marcha los signos de un código, ¿qué sucede cuando el cuerpo se desvía de las condiciones históricas que buscan volverlo el blanco del disciplinamiento, de la docilización, de la domesticación? 
Para Umberto Eco (1972) hay que escuchar hablar a la sociedad en todas las formas que es capaz de hablar aunque no provenga su mensaje de la palabra hablada. La interpretación de María Moreno sobre esta generación nos ofrece una clave: "el cuerpo de los ochenta (...) en vez de hablar hace glosolalia" (María Moreno, 2003, p. 5). La glosolalia como un lenguaje que se vuelve ininteligible, compuesto de palabras inventadas, pero también como esa lengua que surge en los cultos dionisíacos, como resultado de estados de trance, de éxtasis o de júbilo. Si aquellas guaridas para el "Indio" Solari, líder de la banda de rock Patricio Rey y sus Redonditos de Ricota, eran el lugar de cobijo y resguardo para los Dionisios, no resulta extraño que el lenguaje corporal vestimentario que emprendieron construyera una lengua dionisíaca, en aquel clima donde reinaba la vibración de un cuerpo gozoso que se encontraba en una suerte de plena potencia de afectación poética. Fue así como pensamos en esos estilos que desacomodaban la tríada cuerpo-vestido-sociedad como una perfomatividad propia de quienes volviéndose extranjeros en la propia lengua la hacen tartamudear (Deleuze, 1980).

Muchos fueron extranjeros dentro de ese lenguaje mayor, el de los códigos sociales vestimentarios y el de la moda, y así sus prácticas vestimentarias se volvieron una lengua que ya no hablaba del modo gramaticalmente correcto que la sociedad esperaba. Era ese balbuceo el que les permitía entonces desencadenar un movimiento inédito de creación, en los confines de ese territorio vestimentario por el que transitaban en condición de extranjería. Melero colocaba el acento en el "modo" como un acto de conciencia y de atención sobre sí mismo. El énfasis estaba puesto en un "modo" de ser en el mundo, en un estilo que lo distanciaba y lo alejaba de la moda en su carácter masivo y homogeneizante. El modo habla desde la diferencia; en él se vislumbran las elecciones y la propia mirada en relación con las múltiples potencialidades que ofrece el vestido. Es el "modo" el que carga al vestido de una experiencia intersubjetiva, imbuida de significados que son personales pero también sociales. Fue ese "modo" el que, a diferencia de la moda, se instaló en una nueva dimensión del tiempo y del espacio y les permitió crear un nuevo lenguaje con tonos y ritmos propios, generando una propia cadencia con la cual hablar y tomar posición.

\section{Notas}

1. En su intento de terminar con los compartimentos del arte burgués que dividen las Bellas Artes de las Artes aplicadas y los artistas de los artesanos, varios artistas de vanguardia propusieron equiparar la producción de obras de arte con la creación de trajes y vestidos. El Manifiesto de la Moda Femenina Futurista, las prendas confeccionadas por los surrealistas y los textiles de los constructivistas soviéticos en los años posteriores a la revolución bolchevique son algunas de las propuestas estéticas que desafiaron los límites del "arte puro" pasando del lienzo en el cabellete al lienzo en un cuerpo-vestido, o directamente a la creación de diseños textiles pensados como obras que devuelven el arte a la vida cotidiana. Trataban de reivindicar, así, tanto una moda contra-comercial como una praxis creadora libre de las diferencias y las jerarquías que organizan el trabajo y las disciplinas artísticas en la sociedad capitalista (Stern, 2004).

2. El evento fue filmado y fotografiado, ambos registros se encuentra disponible en: http:// archivosenuso.org/. En un costado del lugar se había montado una suerte de precario "estudio" con cartones donde los participantes eran fotografiados antes o después de salir a escena por los cuatro fotógrafos convocados esa noche para dejar registro del evento. En el caso de la foto de Batato vestido con El papelón, la toma pertenece a la fotógrafa Julieta Steimberg. 
3. Como sostiene el Manifiesto que escribieron quienes organizaron el evento aquella noche: "La propuesta es que cada uno se produzca o produzca a ALGUIEN como Obra de Arte, como Imagen Viva, que respira, camina y habla. No importa que el look sea clásico o invento demencial sino que tenga carácter. Ser uno o ser otros. El cuerpo, una superficie recorrida por la sorpresa de lo imposible. La máscara como cara y la vestimenta como extensión del cerebro. Mensaje portátil, políticas de la apariencia pública, teatro al instante, moda sin dictadores. Contra la tristeza del pobre disfraz cotidiano, el lujo de una imagen intensa".

4. El aceite industrial o silicona industrial, se usa en maquinarias y generalmente es un lubricante en forma gelificada, que al colocarlo en el cuerpo comienza a infiltrar los tejidos que no están inyectados y puede llegar hasta la piel, hacer úlceras y producir muchas complicaciones. Las travestis con menores posibilidades económicas para pagar una operación estética recurren a estas intervenciones que se desarrollan normalmente en forma muy precaria y, en algunos casos, ellas mismas se aplican las inyecciones con fines estéticos. Batato Barea, Alejandro Urdapilleta y Humberto Tortonese en Parakafé en Archivos de La Peli de Batata, dirigida por Goyo Anchou y Peter Pank y producida por Mad Crampi donde se ve a Batato mostrando las tetas a pedido de sus compañeros y del público: https:// www.youtube.com/watch?v=qC3bJ3xE10c (minuto 4 del video).

\section{Bibliografía}

Baudelaire, C. (1994). El pintor de la vida moderna. Madrid: Murcia.

Bevacquea, Guillermina (2013). "Memorabilida de Batato por Seedy Gonzalez Paz. Archivos en democracia", Conferencias de la Universidad Nacional de Córdoba, "Perspectivas y debates actuales a 30 años de la democracia" I Congreso Internacional de Ciencias Sociales y Humanidades, Córdoba.

Benjamin, W. (1972). Iluminaciones II. Madrid: Taurus. (2005). Libro de los Pasajes. Madrid: Akal.

Calveiro, P. (1998). Poder y desaparición. Buenos Aires: Colihue.

Deleuze, G. (1996). Crítica y clínica. Barcelona: Anagrama.

Dubatti, J. (1995). Batato Barea y el nuevo teatro argentino. Buenos Aires: Editorial Planeta.

Durkheim, E. (1982) Las reglas del método sociológico. Madrid: Orbis.

Eco, U. (1972). El hábito hace al monje. Barcelona: Editorial Lumen Ramón Miquel y Planas.

Entwistle, J. (2002). El cuerpo y la moda. Una visión sociológica. Barcelona: Paidós.

Flügel, J. (1964). Psicología del vestido. Buenos Aires: Paidós.

Freira, S. (2001). Era cualquier cosa, menos light. Página/12- sección Radar. Recuperado el 15 de mayo de 2017, de http://www.pagina12.com.ar/2001/01-12/01-12-06/pag33.htm 
González, A (2014). Fiestas oficiales por el Día del Estudiante-Día de la Juventud en la última dictadura argentina. La Estudiantina de 1980 en Córdoba. Estudios sobre juventudes en Argentina III: De las construcciones discursivas sobre lo juvenil hacia los discursos de las y los jóvenes, Coord. Borobia, Raquel. Neuquén: Edit. Publifadecs.

Ministerio de Educación de la Nación Argentina. Pensar la dictadura. Terrorismo de Estado en la Argentina, Buenos Aires, Argentina, 2010. Recuperado el 23 de febrero de 2015, de http://repositorio.educacion.gov.ar/dspace/bitstream/handle/123456789/55770/ Pensar_La_Dictadura\%20\%282\%29.pdf?sequence=1

Lescano, V. (2010). Pret-a-rocker, Moda y Rock en la Argentina. Buenos Aires: Ed. Planeta.

Longoni, A. (2013). Incitar al debate, a una red de colaboraciones, a otro modo de hacer. Afuera, № 13(2). Recuperado el 24 de mayo de 2017, de http://www.revistaafuera.com/ articulo.php?id=273\&nro=13

(2012). Museos bailables, en catálogo de la muestra Perder la forma humana. Una imagen sísmica de los años ochenta en América Latina. Madrid: MNCARS-RCS, 189-196.

Lucena, D., y Laboureau, G. (2014). Estéticas disruptivas en el arte durante la última dictadura y los 80. Revista de la Facultad de Ciencias Sociales, № 85, 59-65.

(2015). El rol del cuerpo-vestido en la ruptura estética de Virus durante los últimos años de la dictadura militar. Música Hodie, N² 2, 176-191.

. (2016). Modo mata moda. Arte, cuerpo y (micro)política en los 80. Buenos Aires: EDULP. Moreno, M. (2003). La generación del ochenta. Página 12- sección Radar. Recuperado el 31 de mayo de 20017, de https://www.pagina12.com.ar/diario/suplementos/radar/9- 1149-2003-12-28.html (2011). Fresco y Batato. Página 12- sección Radar. Recuperado el 27 de mayo de 2017, de http://www.pagina12.com.ar/diario/suplementos/radar/9-7077-2011-06-05.html

Noy, F. (2006). Te lo juro por Batato. Buenos Aires: Libros del Rojas (UBA).

Oybin, M. (2015). Las cosas que dejó. Página 12-sección Radar. Recuperado el 12 de mayo de 2017 http://www.pagina12.com.ar/diario/suplementos/radar/9-10811-2015-08-10.html

Perlongher, N. (1983). Nena, llévate un saquito. Alfonsina, N² 2, p.13.

Pujol, S. (2011). Historia del baile. De la milonga a la disco. Buenos Aires: El Gourmet Musical.

Riviere, M. (1994). Moda: ¿comunicación o incomunicación? Barcelona: Paidós.

Saulquin, S. (2011). Historia de la moda argentina. Del miriñaque al diseño de autor. Buenos Aires: Grupo Editorial Planeta.

Stern, R. (2004). Against Fashion. Clothing as art, 1850-1930. Cambridge: The MIT Press, 
Stallybrass, P. (1998). "Marx's coat”. En Border fetishisms: material objects in unstable spaces, Ed. Spyer, Patricia. London: Routledge.

Trerotola, D. (2011). Pezón, pezón, qué grande sos. Página 12 - sección Radar. Recuperado el 23 de mayo de 2017, de http://www.pagina12.com.ar/diario/suplementos/soy/1-1826- 2011-02-05.html

Viola, O. (1998). Omar Viola. Un creador permanente. San Telmo y sus alrededores, № 10, 3-5.

Wilde, O. (1894). Phrases And Philosophies For The Use Of The Young. The Chameleon, Oxford University Journal, número único. Recuperado el 16 de noviembre de 2016, de http://www.bl.uk/collection-items/thechameleon

\section{Entrevistas}

Ana Torrejón, entrevista realizada por Daniela Lucena y Gisela Laboureau, Buenos Aires, Argentina, agosto de 2011.

Ana Torrejón, entrevista realizada por Daniela Lucena, Buenos Aires, Argentina, septiembre de 2014.

Claudia Sinesi, entrevista realizada por Daniela Lucena y Gisela Laboureau, Buenos Aires, Argentina, mayo de 2011.

Daniel Melero, entrevista realizada por Daniela Lucena, Buenos Aires, Argentina, agosto de 2011.

Katja Alemann, entrevista realizada por Daniela Lucena y Gisela Laboureau, Tigre, Argentina, octubre de 2011.

Manuel Hermelo, entrevista realizada por Malala González, Buenos Aires, Argentina, mayo de 2008 y junio de 2015.

Marula Dicomo, entrevista vía Skype realizada por Daniela Lucena, Berlín, Alemania / Buenos Aires / Argentina, febrero de 2016.

Pablo Dreizik, entrevista realizada por Daniela Lucena, Buenos Aires, Argentina, febrero de 2017.

Vanesa Weinberg, entrevista realizada por Gisela Laboureau, Tigre, Argentina, febrero de 2016.

Abstract: This work refers to a series of aesthetic practices developed by different actors in the field of art, rock and theater in the $80 \mathrm{~s}$ in the City of Buenos Aires, which were reconstructed from interviews and the search of photographs and videos of the time. These are experiences in which the body-dress played a central role: as a support for the artistic, as a territory of resistance and indiscipline, as a canvas, as an instrument of protest, as a vehicle for being (with others) in the world. The analysis of these disruptive aesthetics will be done paying special attention to the dress practices developed by the artists, based on the hypothesis that they can be read in an unprecedented cross between art, fashion and (micro) politics.

Key words: dress practices - fashion - counterculture - rock - performance. 
Resumo: Este trabalho refere-se a uma série de práticas estéticas desenvolvidas por diferentes atores no campo da arte, do rock e do teatro na década de 80 na cidade de Buenos Aires. Eles foram reconstruídos desde entrevistas em profundidade e fotografías, imagens e vídeos da época. Eles são experiências em que o corpo vestido desempenhou um papel central: como suporte ao artístico, como território de resistência e indisciplina, como instrumento de protesto, como superfície de exploração e como veículo no mundo. A análise dessas estéticas disruptivas foi feita com especial atenção às vestimentas desenvolvidas pelos artistas. A hipótese principal é que elas podem ser lidas desde o cruzamento inédito entre arte, moda e (micro) política.

Palavras-chave:

Vestido - Moda - Contracultura - Rock - Performance.

[Las traducciones de los abstracts fueron supervisadas por el autor de cada artículo]

Vestimentas indisciplinadas en la escena contracultural de los años 80 fue publicado de la página 143 a página160 en Cuadernos del Centro de Estudios de Diseño y Comunicación №76 